\title{
Penetrating mitral annular abscess ruptured into the left atrium: a rare cause of mitral regurgitation
}

\author{
Gopal Chandra Ghosh, ${ }^{1}$ Amal Paul, ${ }^{2}$ Anoop George Alex, ${ }^{2}$ Paul V George ${ }^{2}$
}

'Department of Cardiology, Christian Medical College Hospital, Vellore, Tamil Nadu, India

${ }^{2}$ Christian Medical College and Hospital Vellore, Vellore, Tamil Nadu, India

\section{Correspondence to} Dr Gopal Chandra Ghosh, gcghosh86@gmail.com

Accepted 7 February 2017

\section{DESCRIPTION}

A man aged 27 years from Bangladesh was referred to our centre for evaluation of fever of unknown origin of 3 months duration. There was a history of progressively increasing dyspnoea of NYHA functional class II for 25 days. He had received antibiotic therapy for a week prior to his presentation to us. Physical examination revealed muffled first heart sound with loud pulmonary component of second heart sound. A grade IV/VI (Levine grade) pan systolic murmur was heard over the apex, radiating to the left axillae. There were no clinical stigmata of infective endocarditis. Blood cultures were sterile. ECG showed sinus rhythm with left atrial enlargement and chest X-ray was suggestive of moderate cardiomegaly (cardiothoracic ratio 65\%). Transthoracic echocardiogram (TTE) (figures 1 and 2 and video 1) revealed features of severe mitral regurgitation, with

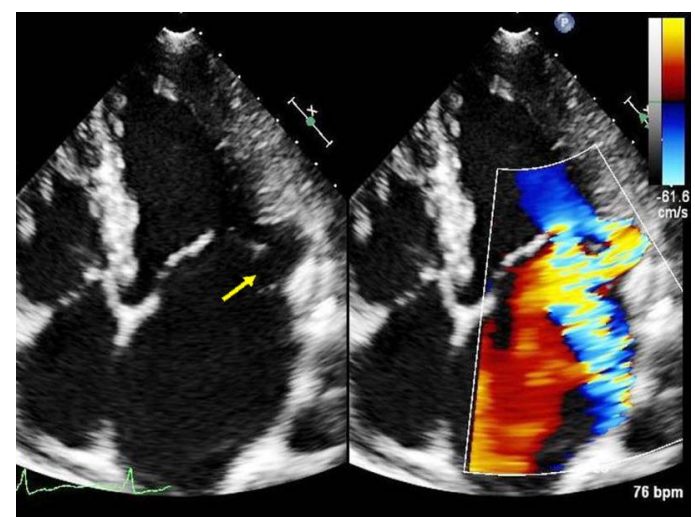

Figure 1 Apical four-chamber view showing a ruptured abscess cavity involving posterior mitral annulus communicating with the left atrium (yellow arrow). Two mitral regurgitation jets noted one central jet and another through the abscess cavity.

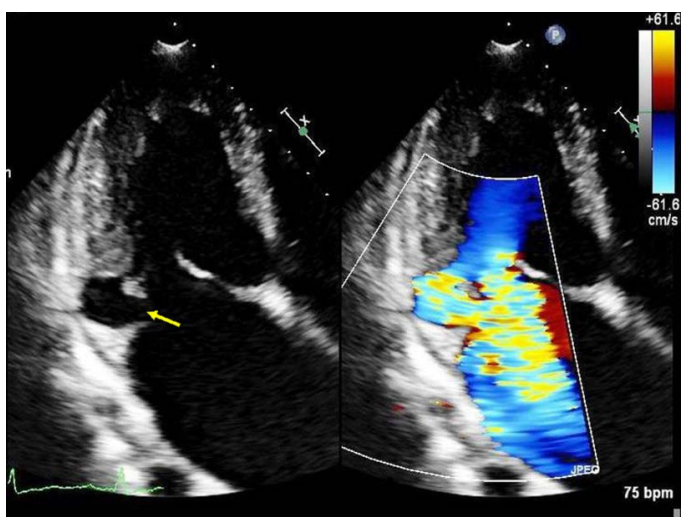

Figure 2 Modified apical four-chamber view focused on the left atrium and left ventricle showing two jets of mitral regurgitation. a ruptured abscess cavity (yellow arrow) involving the posterior mitral leaflet and annulus, communicating with the left atrium. The left ventricle and left atrium were dilated. Transoesophageal echocardiogram confirmed the findings of TTE (video 2).

Periannular extension of the endocarditis occurs in $10-40 \%$ of cases and is more commonly encountered after prosthetic valve surgery. ${ }^{1}$ Paravalvular abscess formation is commoner in the aortic valve when compared with mitral valve, and is associated with conduction abnormalities. The presence of valve ring abscesses in patients with infective endocarditis increases morbidity and mortality. ${ }^{2}$ Visualisation of the abscess cavity is often inadequate with transthoracic echocardiogram (TTE) with a sensitivity of around $30 \%$, whereas transoesophageal echocardiography (TEE) has a sensitivity of around $90 \% .^{3}$ Our case depicts an instance where a meticulously performed TTE clinched the complete diagnosis, and TEE contributed no additional information. Our patient underwent successful mitral valve replacement.

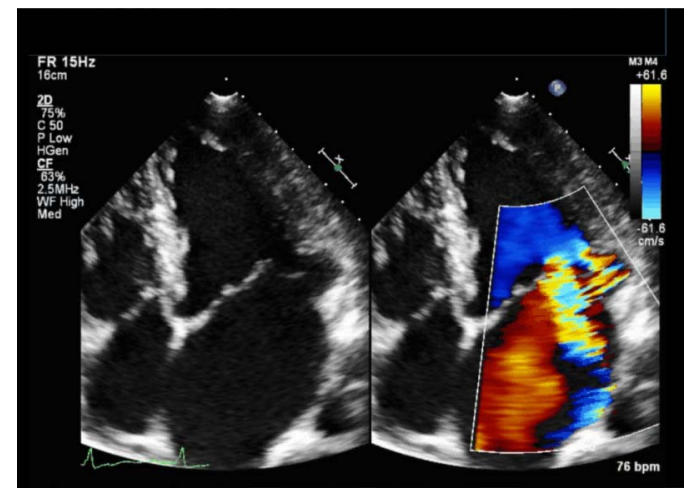

Video 1 Transthoracic echocardiogram showing mitral regurgitation jets and abscess cavity.

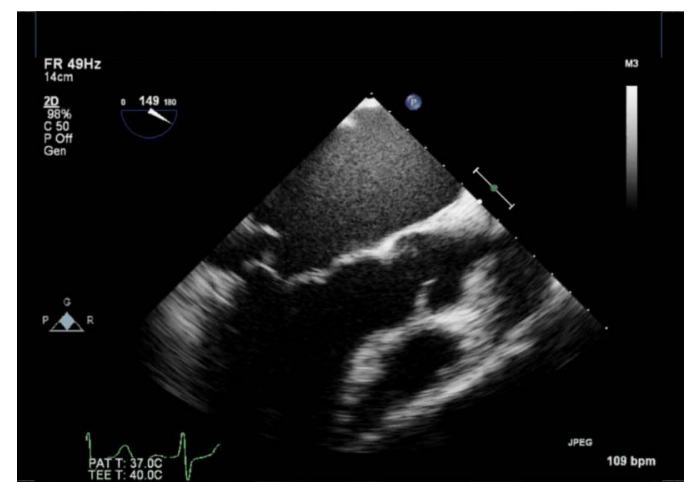

Video 2 Transoesophageal echocardiography (mid-oesophageal long-axis view) showing abscess cavity involving the posterior mitral annulus. 


\section{Learning points}

- Mitral annular abscess with rupture into the left atrium causing severe mitral regurgitation is a rare complication of infective endocarditis.

- Transoesophageal echocardiography is the gold standard for diagnosis.

- Meticulous transthoracic echocardiography can clinch the complete diagnosis in selected cases.

Contributors GCG is the primary author and performed writing, editing and literature search. AP helped in editing and case discussion. AGA helped in editing. PVG is the senior author involved in editing and supervising manuscript.
Competing interests None declared.

Patient consent Obtained.

Provenance and peer review Not commissioned; externally peer reviewed.

\section{REFERENCES}

1 Ekici $F$, Kocabaş $A$, Aktaş $D$, et al. Native aortic valve endocarditis complicated by pseudoaneurysm of mitral-aortic intervalvular fibrosa. Echocardiography 2014;31: E60-3.

2 Choussat R, Thomas D, Isnard R, et al. Perivalvular abscesses associated with endocarditis; clinical features and prognostic factors of overall survival in a series of 233 cases. Perivalvular Abscesses French Multicentre Study. Eur Heart $J$ 1999:20:232-41.

3 Daniel WG, Mügge A, Martin RP, et al. Improvement in the diagnosis of abscesses associated with endocarditis by transesophageal echocardiography. $N$ Engl J Med 1991;324:795-800.

Copyright 2017 BMJ Publishing Group. All rights reserved. For permission to reuse any of this content visit http://group.bmj.com/group/rights-licensing/permissions.

BMJ Case Report Fellows may re-use this article for personal use and teaching without any further permission.

Become a Fellow of BMJ Case Reports today and you can:

- Submit as many cases as you like

- Enjoy fast sympathetic peer review and rapid publication of accepted articles

- Access all the published articles

- Re-use any of the published material for personal use and teaching without further permission

For information on Institutional Fellowships contact consortiasales@bmjgroup.com

Visit casereports.bmj.com for more articles like this and to become a Fellow 